\title{
Nitrogênio e enxofre na adubação e em folhas diagnósticas e raízes do capim- braquiária em degradação ${ }^{1}$
}

\author{
Edna Maria Bonfim-Silva², Francisco Antonio Monteiro ${ }^{3}$
}

1 Projeto financiado pela FAPESP.

2 Programa de Pós-Graduação em Solos e Nutrição de Plantas - ESALQ/USP. Departamento de Ciência do Solo. Av. Pádua Dias, 11, Caixa Postal 9, Piracicaba, SP.

${ }^{3}$ Departamento de Ciência do Solo-ESALQ/USP.

RESUMO - Objetivou-se estudar os efeitos das combinações de nitrogênio com enxofre nas concentrações de nitrogênio e enxofre e na relação de nutrientes nas folhas diagnósticas e nas raízes do capim-braquiária (Brachiaria decumbens Stapf.) em degradação antes das adubações. Foram coletados cilindros com planta + solo em uma pastagem em degradação em área de Neossolo Quartzarênico. O experimento foi conduzido em casa de vegetação no período de novembro de 2003 a março de 2004. Foram utilizadas cinco doses de nitrogênio $\left(0 ; 100 ; 200 ; 300\right.$ e $\left.400 \mathrm{mg} / \mathrm{dm}^{3}\right)$ e cinco doses de enxofre $(0 ; 10 ; 20$; 30 e $40 \mathrm{mg} / \mathrm{dm}^{3}$ ), as quais foram combinadas em estudo de superfície de resposta, em desenho experimental composto central modificado de um fatorial $5^{2}$ fracionado. Realizaram-se três cortes em intervalos de 30 dias. O valor SPAD no capimbraquiária depende da combinação de doses de nitrogênio e enxofre apenas no primeiro corte; no segundo e no terceiro corte, há apenas efeito isolado das doses de nitrogênio. A baixa relação nitrogênio:enxofre observada na ausência da aplicação do nitrogênio comprova maior deficiência de nitrogênio que de enxofre no capim-braquiária em recuperação. A aplicação de enxofre, e principalmente de nitrogênio, influencia o estado nutricional e a recuperação do capim-braquiária.

Palavras-chave: Brachiaria decumbens, concentração, relação nitrogênio:enxofre

\section{Nitrogen and sulphur in the fertilization and in diagnostic leaves and in degrading roots of signal grass}

\begin{abstract}
It was aimed to study the effects of nitrogen and sulphur combinations on the concentrations of nitrogen and sulphur and on the relationship of nutrients in diagnostic leaves and in degrading roots of signal grass (Brachiaria decumbens Stapf.) before fertilizations. It was collected cylinders with plant + soil from a degrading pasture in an area of typic Quartzpsamment soil. The experiment was carried out in a greenhouse from November 2003 to March 2004. Five levels of nitrogen $\left(0 ; 100 ; 200 ; 300\right.$ and $\left.400 \mathrm{mg} / \mathrm{dm}^{3}\right)$ and five doses of sulfur $\left(0 ; 10 ; 20 ; 30\right.$ and $\left.40 \mathrm{mg} / \mathrm{dm}^{3}\right)$ were combined in a study of response surface in a modified central composite experimental design of a fractionated $5^{2}$ factorial. Three cuts were done in 30-day intervals. The SPAD value in signal grass depends on the combination of nitrogen and sulphur doses only in the first cut; on the second and third cut, there are only the isolated effects of nitrogen doses. The low nitrogen:sulfur ratio observed in the absence of application of nitrogen evidences the higher deficiency of nitrogen than of sulphur in the recovering signal grass. The application of sulphur, and mainly of nitrogen, influences the nutritional status and recovery of signal grass.
\end{abstract}

Key Words: Brachiaria decumbens, concentration, nitrogen:sulphur ratio

\section{Introdução}

O suprimento de nutrientes constitui-se importante fator na nutrição da planta forrageira, tendo em vista que a disponibilidade de nutrientes exerce grande influência na nutrição da planta, que se reflete no desenvolvimento vegetal e na recuperação do capim. Nesse contexto, a deficiência de nitrogênio tem sido apontada como uma das principais causas da degradação de pastagens e também existe a necessidade de se atentar para o enxofre, principalmente quando se aplicam doses elevadas de nitrogênio (Silveira et al., 2005).

A maior parte das pesquisas com plantas forrageiras enfatiza o desenvolvimento da parte aérea das plantas, deixando as raízes como um componente "escondido" e não abordando a interdependência entre estas partes dos vegetais. No entanto, é sabido que há necessidade de sistema radicular vigoroso, tanto para a produtividade 
quanto para a longevidade da pastagem. A carência de informações relativas ao sistema radicular das plantas forrageiras tem sido destacada (Cecato et al., 2004; Sarmento et al., 2008). No entanto, no que diz respeito ao aspecto de nutrientes nas raízes, as informações são ainda mais escassas quando comparadas aos aspectos produtivos.

O nitrogênio é o grande responsável pela melhoria nas características nutricionais das gramíneas forrageiras e o seu efeito tem mostrado ser dependente do enxofre (Mattos \& Monteiro, 2003). O enxofre, assim como o nitrogênio, é de extrema importância para a nutrição da planta forrageira, por ser componente dos aminoácidos cisteína, cistina e metionina. Além disso, faz parte da ferrodoxina, molécula transferidora de elétrons e envolvida na fotossíntese (Mengel \& Kirkby, 2001). O equilíbrio entre as quantidades de nitrogênio e de enxofre no solo e na planta é importante porque reflete no estado nutricional do vegetal.

Com base na hipótese de que determinadas combinações de nitrogênio e enxofre na adubação influenciam as características nutricionais do capim-braquiária (Brachiaria decumbens Stapf.), contribuindo para a avaliação do estado nutricional desses dois nutrientes no capim, objetivou-se estudar os efeitos das combinações de nitrogênio e enxofre na concentração e na relação desses nutrientes nas folhas diagnósticas (lâminas de folhas recém-expandidas) e nas raízes desse capim em recuperação.

\section{Material e Métodos}

O experimento foi realizado em casa de vegetação em Piracicaba, São Paulo, no período de novembro de 2003 a março de 2004. Foram coletadas amostras de capimbraquiária + solo em cilindros de $15 \mathrm{~cm}$ de diâmetro e $20 \mathrm{~cm}$ de profundidade, em um Neossolo Quartzarênico, numa pastagem em degradação, no município de Santa Maria da Serra, SP. Essas amostras de solo e plantas foram colocadas em vasos plásticos, conforme técnica descrita por Mattos \& Monteiro (2003). Durante o período de 30 dias as plantas foram adaptadas e os vasos homogeneizados nos blocos experimentais, utilizando-se o critério de uniformidade das plantas e local de coleta das amostras em campo. Realizou-se um corte de uniformização das plantas, a $5 \mathrm{~cm}$ do colo, e aplicaram-se as doses de nitrogênio e de enxofre.

As características químicas da amostra superficial (0-20 cm) do solo coletado na área de pastagem em degradação, antes da aplicação dos tratamentos, foram: $\mathrm{pH}$ $\left(\mathrm{CaCl}_{2}\right)=5,43$; M.O. e N-total $=28$ e $1,75 \mathrm{~g} / \mathrm{kg}$, respectivamente; $\mathrm{N}-\mathrm{NH}_{4}{ }^{+}$e $\mathrm{N}-\mathrm{NO}_{3}{ }^{-}=8,40$ e $2,80 \mathrm{mg} / \mathrm{kg}$, respectivamente; P-resina e S-sulfato $=4,03$ e $4,32 \mathrm{mg} / \mathrm{dm}^{3}$, respectivamente; $\mathrm{S}$-total = 150 g/kg; K; Ca; $\mathrm{Mg} ; \mathrm{H}+\mathrm{Al}$; SB е СTC = 2,28; 14,60; 10,40; 28,20; 27,28 e 55,48 $\mathrm{mmol}_{\mathrm{c}} / \mathrm{dm}^{3}$, respectivamente; $\mathrm{V}$ e $\mathrm{m}=49,17$ e $11,83 \%$, respectivamente.

Foram combinadas cinco doses de nitrogênio $(0 ; 100$; 200; 300 e $\left.400 \mathrm{mg} / \mathrm{dm}^{3}\right)$ com cinco de enxofre $(0 ; 10 ; 20 ; 30$ e $40 \mathrm{mg} / \mathrm{dm}^{3}$ ), em estudo de superfície de resposta, baseado em desenho experimental composto central modificado de um fatorial $5^{2}$ fracionado, de acordo com Littell \& Mott (1975). Assim, empregaram-se 13 combinações de nitrogênio com enxofre (em mg/ $\left.\mathrm{dm}^{3}\right): 0-0 ; 0-20 ; 0-40 ; 100-10 ; 100-30$; 200-0; 200-20; 200-40; 300-10; 300-30; 400-0; 400-20 e 400-40. O nitrogênio foi fornecido como nitrato de amônio $\left(\mathrm{NH}_{4} \mathrm{NO}_{3}\right)$ e o enxofre como sulfato de cálcio $\left(\mathrm{CaSO}_{4} \cdot 2 \mathrm{H}_{2} \mathrm{O}\right)$, sendo a quantidade de cálcio (Ca) equilibrada em todas as parcelas experimentais pelo emprego de cloreto de cálcio $\left(\mathrm{CaCl}_{2}\right)$. Após o corte de uniformização foram aplicados: $200 \mathrm{mg} / \mathrm{dm}^{3}$ de fósforo, $150 \mathrm{mg} / \mathrm{dm}^{3}$ de potássio e $50 \mathrm{mg} \mathrm{dm}^{-3}$ de magnésio a partir das seguintes fontes: $\mathrm{CaH}_{2} \mathrm{PO}_{4}, \mathrm{KH}_{2} \mathrm{PO}_{4}$, $\mathrm{KH}_{2} \mathrm{PO}_{4}, \mathrm{KCl}$ e $\mathrm{MgCl}_{2} \cdot 6 \mathrm{H}_{2} \mathrm{O}$. As adubações com nitrogênio, enxofre e potássio foram repetidas após cada corte das plantas, enquanto a adubação com magnésio foi de $20 \mathrm{mg} / \mathrm{dm}^{3}$, em razão da não aplicação de fósforo a partir do primeiro corte e em consequência da diminuição no fornecimento de cálcio após o primeiro corte das plantas. A adubação básica com os micronutrientes foi efetuada com $\mathrm{H}_{3} \mathrm{BO}_{3}$ de $1,5 \mathrm{mg} / \mathrm{dm}^{3}, \mathrm{CuCl}_{2} \cdot 2 \mathrm{H}_{2} \mathrm{O}$ de $2,5 \mathrm{mg} / \mathrm{dm}^{3}, \mathrm{ZnCl}_{2}$ de $2,0 \mathrm{mg} / \mathrm{dm}^{3}$ e de $\mathrm{Na}_{2} \mathrm{MoO}_{4} \cdot 2 \mathrm{H}_{2} \mathrm{O}$ de $0,25 \mathrm{mg} / \mathrm{dm}^{3}$, realizada apenas após o corte de uniformização das plantas. As adubações com macronutrientes foram estabelecidas em função da análise de solo e as adubações com micronutrientes adaptadas de Mattos \& Monteiro (2003).

Os vasos foram distribuídos segundo o delineamento experimental de blocos ao acaso, com quatro repetições, e a temperatura média na casa de vegetação durante o período experimental foi de $30^{\circ} \mathrm{C}$. A umidade em cada vaso foi mantida por meio de um sistema autoirrigante por tensão controlada, composto por cápsula de porcelana porosa (Bonfim-Silva et al., 2007).

Vinte dias após cada aplicação das combinações de nitrogênio e enxofre foi realizada a leitura das unidades SPAD (com o emprego do clorofilômetro SPAD-502) em cinco lâminas folhas diagnósticas (folhas recémexpandidas: lâmina + 1 e lâmina + 2 do ápice para a base das plantas, em cada unidade experimental no primeiro, segundo e terceiro cortes). Assim, os espectros de absorção foram determinados com base na quantidade de luz transmitida pela folha amostrada em dois comprimentos de onda, sendo nas áreas do vermelho em $650 \mathrm{~nm}$ e em infravermelho em 940 nm, onde os picos de absorção são máximos e mínimos, respectivamente. Nesse equipamento a luz transmitida é convertida em sinais elétricos, que são digitalizados e 
microprocessados para cálculo em valor SPAD da medida de clorofila (Minolta Camera Co, 1989).

Foram realizados três cortes na parte aérea das plantas, a cada 30 dias após a aplicação das doses dos nutrientes. A altura de corte foi de $5 \mathrm{~cm}$ do colo da planta para o primeiro e segundo cortes e rente ao colo da planta no terceiro corte. Após o terceiro corte das plantas, as raízes foram separadas do solo e lavadas em água corrente e água desionizada sobre um conjunto de peneiras com malhas de 1,00 e $0,25 \mathrm{~mm}$. O material vegetal coletado nos três cortes foi secado em estufa de circulação forçada de ar, à temperatura de $65-70^{\circ} \mathrm{C}$, até massa constante, sendo posteriormente pesado em balança de precisão.

As concentrações de nitrogênio total e de enxofre total foram determinadas nas folhas diagnósticas dos três cortes e nas raízes do capim, segundo a metodologia descrita por Sarruge \& Haag (1974). A relação nitrogênio:enxofre em cada tipo de tecido vegetal foi obtida por meio de cálculo.

Todos os resultados receberam o recomendado tratamento estatístico, com análise em superfície de resposta por meio do Statistical Analysis System (SAS, 1996). Inicialmente foi realizada a análise de variância para as combinações das doses de nitrogênio e de enxofre e, em função da significância da interação dessas doses no teste $\mathrm{F}$, efetuou-se o estudo de regressão polinomial (superfície de resposta) por meio do procedimento RSREG. Nos casos em que a interação doses de nitrogênio $x$ enxofre não foi significativa, efetuou-se o estudo de regressão de primeiro e segundo graus, por meio do comando GLM. Utilizou-se o nível de significância de 5\% em todos os testes estatísticos.

No caso do estudo de regressão polinomial, as doses de nitrogênio e de enxofre responsáveis pelos máximos valores foram obtidas pela saída de resultados (output) do programa SAS. Para o estudo de regressão de segundo grau as doses de nitrogênio ou de enxofre responsáveis pelos máximos valores foram obtidas por meio de derivada.

\section{Resultados e Discussão}

No primeiro corte, a análise de variância para o valor SPAD nas lâminas de folhas diagnósticas foi significativa para interação doses de nitrogênio $\times$ enxofre, ajustando-se a modelo polinomial de regressão. Por meio do estudo de superfície de resposta constatou-se que a dose de nitrogênio de $526 \mathrm{mg} / \mathrm{dm}^{3}$ associada à dose de enxofre de $14 \mathrm{mg} / \mathrm{dm}^{3}$, proporcionaria o máximo valor SPAD (Figura 1A). Essa dose de nitrogênio para o máximo valor SPAD no primeiro corte excedeu a maior dose do intervalo experimental.
Os resultados de valor SPAD observados no primeiro corte do capim-braquiária demonstram a necessidade do equilíbrio na relação nitrogênio:enxofre. Esse equilíbrio entre as doses de nitrogênio e de enxofre foi também

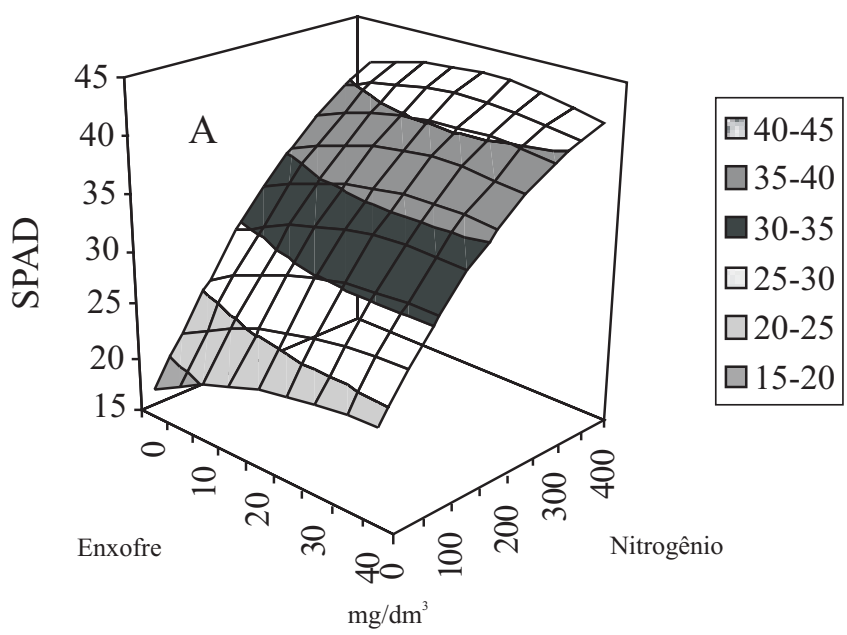

$\hat{\mathrm{Y}}=17,3698+0,0928^{* * *} \mathrm{~N}-0,000083^{* * *} \mathrm{~N}^{2}-0,00039^{*} \mathrm{NS}+0,3206^{* *} \mathrm{~S}-0,0041 * \mathrm{~S}^{2}$ $\mathrm{R}^{2}=0,90$
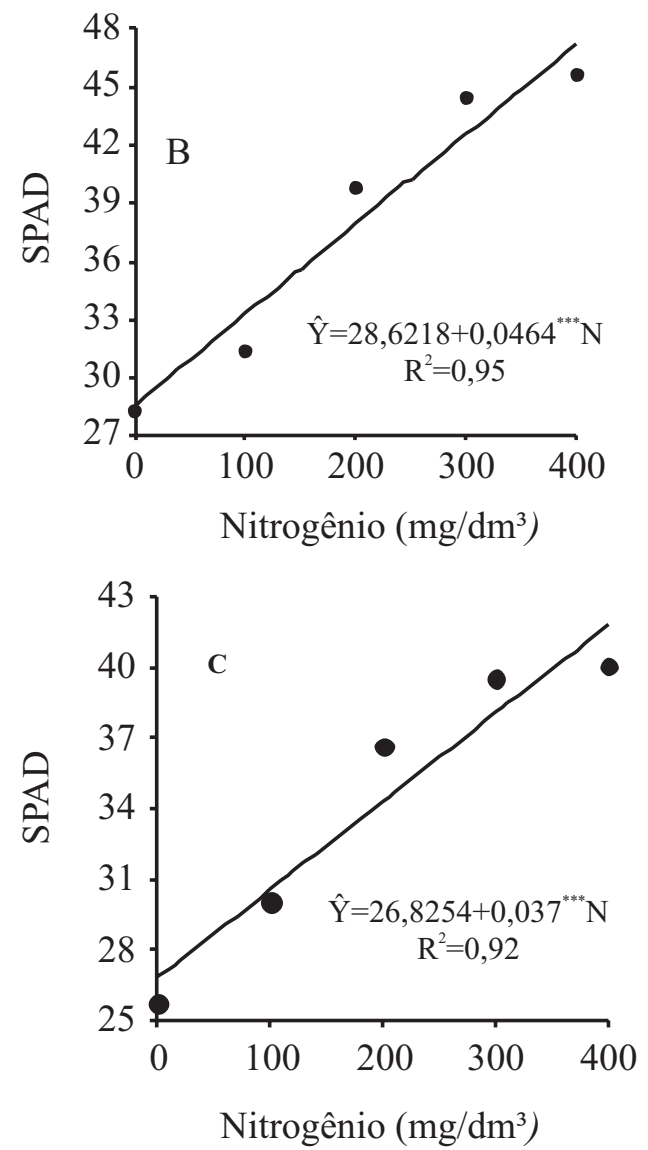

***; ** e * Significativo a 0,$1 ; 1$ e $5 \%$, respectivamente

Figura 1 - Valor SPAD em folhas diagnósticas de capim-braquiária no primeiro corte (A), em função das combinações de doses de nitrogênio e de enxofre, e no segundo e terceiro cortes (B e C) em função das doses de nitrogênio. 
verificado por Rodrigues etal.(2003), Batista \& Monteiro (2007) e Mattos \& Monteiro (2003).

No segundo e terceiro cortes, houve efeito significativo para o valor SPAD nas lâminas de folhas diagnósticas apenas para as doses de nitrogênio, com os resultados ajustando-se a modelo linear de regressão nos dois cortes do capim (Figuras 1B e 1C). Na maior dose de nitrogênio empregada no experimento $\left(400 \mathrm{mg} / \mathrm{dm}^{3}\right)$, os valores SPAD foram de 47 e 42, respectivamente, no segundo e terceiro cortes. No entanto, na ausência da aplicação de nitrogênio os valores SPAD foram 29 e 27, respectivamente para o segundo e terceiro cortes do capim, indicando que a leitura SPAD pode ser utilizada como ferramenta para análise da diagnose nutricional em nitrogênio em gramíneas forrageiras. Essa relação do aumento da leitura SPAD com as doses de nitrogênio pode ser atribuída, principalmente, ao fato de 50 a 70\% do nitrogênio total das folhas serem integrantes de compostos associados aos cloroplastos e ao conteúdo da clorofila nas folhas (Chapman \& Barreto, 1997).

Santos (1997) verificou os máximos valores SPAD de 50 e 52 nas lâminas de folhas diagnósticas do capimbraquiária, para o primeiro e segundo cortes, os quais corresponderam às doses de 330 e 442 mg/L. Entretanto, Abreu \& Monteiro (1999) comparando dias de corte do capim-marandu (Brachiaria brizantha cv. Marandu), relataram que aos 14, 28 e 42 dias de corte, o valor SPAD variou entre 31, 8 e 14 para ausência de nitrogênio e entre 51, 57 e 46 nas doses de nitrogênio de 228, 239 e 302 mg/kg, respectivamente.

Manarin \& Monteiro (2002), estudando capimmombaça (Panicum maximum cv. Mombaça) submetido a doses de nitrogênio, observaram, no primeiro corte do capim, que o valor SPAD variou entre 22 e 47 nas condições de omissão de nitrogênio na solução e a dose de nutriente que proporcionou o máximo valor. Entretanto, no segundo corte da forrageira, constatou-se que os resultados se ajustaram a modelo linear de regressão, assim como no presente trabalho, evidenciando alto requerimento de nitrogênio para as gramíneas forrageiras.

Lavres Jr. \& Monteiro (2006), estudando diagnose nutricional de nitrogênio no capim-aruana (Panicum maximum cv. Aruana) em condições controladas, verificaram que as doses de nitrogênio promoveram variações significativas nos valores SPAD nas folhas diagnósticas do capim, e considerando que, assim como no presente estudo, esta parte da planta pode ser utilizada como o componente morfológico da parte aérea da gramínea forrageira mais indicado para a avaliação do estado nutricional em nitrogênio.

A análise de variância para a concentração de nitrogênio nas folhas diagnósticas do capim-braquiária não apresentou significância para interação doses de nitrogênio × enxofre, nos três cortes estudados. No entanto, foi observada resposta significativa nessa variável para as doses de nitrogênio nos três cortes da gramínea forrageira.

A concentração de nitrogênio nas folhas diagnósticas no primeiro, segundo e terceiro cortes ajustou-se a modelo de regressão de primeiro grau (Figuras 2A, 2B e 2C). Desse modo, a máxima concentração de nitrogênio nessas lâminas foliares foi obtida quando a maior dose de nitrogênio foi aplicada. A variação nessa concentração entre a condição em que não se aplicou nitrogênio e a maior dose do nutriente esteve entre 8,98 e 25,41; 15,33 e 28,17; 13,92 e $30,99 \mathrm{~g} / \mathrm{kg}$, respectivamente, para o primeiro, segundo e terceiro cortes.

Santos (1997) observou variação linear na concentração de nitrogênio nas folhas diagnósticas no primeiro corte do capim-braquiária em implantação e submetido a doses de nitrogênio na solução nutritiva, com variação entre 12,6 e $27,5 \mathrm{~g} / \mathrm{kg}$.

Rodrigues et al. (2003), estudando concentração de nitrogênio nas folhas diagnósticas do capim-braquiária, verificaram que a máxima concentração de nitrogênio ocorreu na aplicação de nitrogênio de 992,7 mg/kg.

Mattos \& Monteiro (2003) observaram incremento linear na concentração de nitrogênio nas folhas diagnósticas do capim-braquiária até a máxima dose de nitrogênio empregada no experimento ( $200 \mathrm{mg} / \mathrm{dm}^{3}$ ).

Batista \& Monteiro (2007), estudando a interação doses de nitrogênio $\times$ enxofre para o capim-marandu, verificaram que as concentrações de nitrogênio nas folhas diagnósticas, no primeiro corte, ajustaram-se ao modelo quadrático de regressão, em função das doses de nitrogênio, com máxima concentração de 31,0 g/kg. No segundo corte do capim, a concentração de nitrogênio ajustou-se a modelo de regressão de primeiro grau, com intervalo de 9,5 e 16,9 g/kg entre a menor e a maior dose de $\mathrm{N}$.

Em estudos realizados por Colozza et al. (2000), com capim-aruana submetido a doses de nitrogênio, foi observado que, à medida que se aumentou a dose de nitrogênio, ocorreu o incremento da concentração de nitrogênio nas folhas diagnósticas do capim, também com ajuste dos resultados a modelo linear de regressão.

Um aspecto importante a ser considerado no presente trabalho é a capacidade responsiva do capim-braquiária à adubação nitrogenada, elevando a concentração de nitrogênio para valores considerados adequados para o desenvolvimento da forrageira (Monteiro, 2005; Silveira et al., 2005) e contribuindo efetivamente para a recuperação da pastagem.

Soares Filho et al. (1992) ponderaram que a maioria das pastagens de capim-braquiária do estado de São Paulo

R. Bras. Zootec., v.39, n.8, p.1641-1649, 2010 

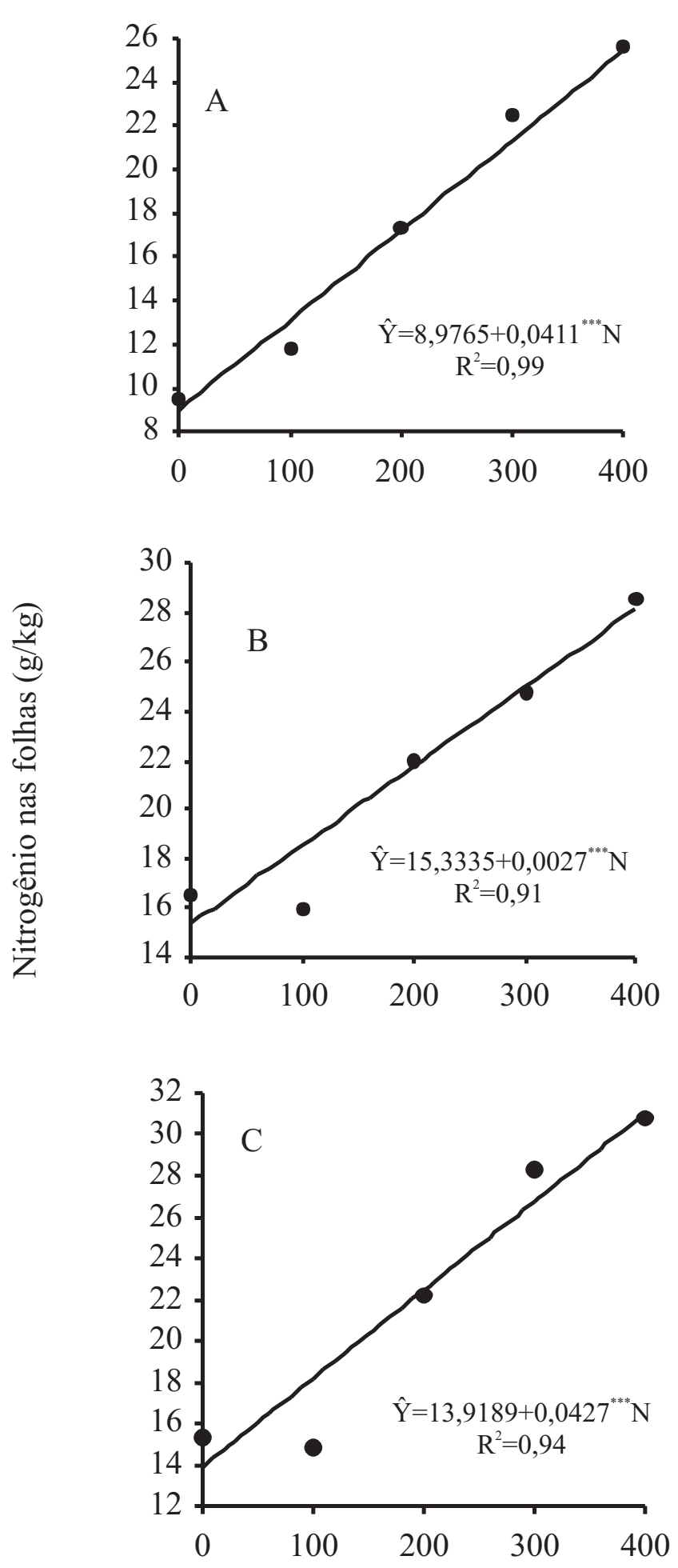

Nitrogênio $\left(\mathrm{mg} / \mathrm{dm}^{3}\right)$

*** Significativo a $0,1 \%$.

Figura 2 - Concentração de nitrogênio, no primeiro (A), segundo (B) e terceiro (C) cortes, em folhas diagnósticas do capim-braquiária adubado com nitrogênio. encontrava-se em estágio de degradação em consequência do esgotamento da fertilidade do solo, associado ao manejo inadequado da planta forrageira. Assim, qualquer nutriente pode ser limitante em determinada condição de pastagem, mas no caso de degradação tem sido frequente a limitação por nitrogênio (Soares Filho, 1993; Mattos \& Monteiro, 2003).

A faixa de concentração de nutrientes tem sido apontada como a que melhor define o estado nutricional das plantas (Bataglia, 1991). No entanto, Werner et al. (1996) apresentaram as faixas adequadas para nove capins e cinco leguminosas tropicais consideradas importantes para o estado de São Paulo, relatando grande amplitude das faixas descritas para apreciáveis parte dos nutrientes, de 12 a 20 g/kg na concentração de nitrogênio.

A interação doses de nitrogênio $\times$ enxofre não foi significativa para a concentração de nitrogênio nas raízes do capim-braquiária. No entanto, respostas significativas foram observadas para as doses de nitrogênio, com ajuste a modelo de regressão de primeiro grau (Figura 3).

Pode-se observar que na ausência de aplicação de nitrogênio a concentração desse nutriente nas raízes foi de $5,86 \mathrm{~g} / \mathrm{kg}$, enquanto que a mais alta concentração $\left(400 \mathrm{mg} / \mathrm{dm}^{3}\right)$ foi de $8,41 \mathrm{~g} / \mathrm{kg}$. Em presença de maior quantidade de nitrogênio no solo, as raízes também passam a funcionar como órgão armazenador desse nutriente (Colozza, 1998).

A máxima concentração de nitrogênio nas raízes, no presente trabalho, situa-se abaixo daquela observada por

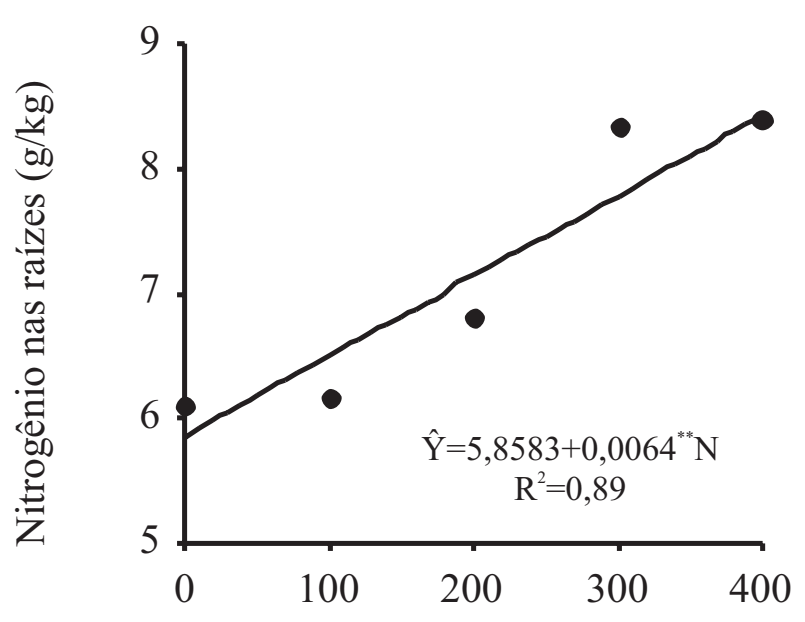

\section{Nitrogênio $\left(\mathrm{mg} / \mathrm{dm}^{3}\right)$}

\footnotetext{
${ }^{* *}$ Significativo a $1 \%$.
}

Figura 3 - Concentração de nitrogênio, após o terceiro corte, em raízes do capim-braquiária adubado com nitrogênio.

R. Bras. Zootec., v.39, n.8, p.1641-1649, 2010 
Santos (1997) na implantação desse capim, quando a concentração máxima de nitrogênio nas raízes foi de 10,90 g/kg. Também na fase de implantação da gramínea, Colozza (1998) observou variação nas concentrações de nitrogênio de 6,55 a 19,37 g/kg nas raízes de capim-mombaça, respectivamente para a ausência de aplicação de nitrogênio e a dose de $400 \mathrm{mg} / \mathrm{kg}$ em Latossolo Vermelho-amarelo. Entretanto, Batista \& Monteiro (2006) demonstraram, por meio de regressão polinomial, que a concentração de nitrogênio no tecido radicular do capim-marandu variou de 2,4 a 29,5 g/kg, no intervalo de doses de nitrogênio de 14 a 462 mg/L na solução nutritiva.

Lavres Jr. \& Monteiro (2002) constataram que a concentração de nitrogênio nas raízes do capim-mombaça variou na faixa de 10,1 a 16,5 g/kg nas combinações de mais baixas doses de nitrogênio e de potássio até as mais altas doses desses dois nutrientes. No entanto, a concentração mais elevada de nitrogênio nas raízes foi de $24,5 \mathrm{~g} / \mathrm{kg}$, encontrada nas doses de nitrogênio e de potássio de 462,0 e 19,5 mg/L, respectivamente.

Pode-se observar que em trabalhos com implantação de pastagens de capins (Santos, 1997; Colozza, 1998; Batista \& Monteiro, 2006) que a concentração de nitrogênio nas raízes chegou a valores bem mais elevados que os observados no presente trabalho. Isso pode ter ocorrido devido ao fato de que, quando se implanta o capim e se fornece o nitrogênio, está se garantindo adequado desenvolvimento das raízes e consequentemente maior capacidade de absorção, o que resulta em maior concentração no tecido. No presente trabalho, as condições iniciais das raízes já eram limitantes para a absorção de nutrientes, uma vez que a disponibilidade de nitrogênio era baixa, e o sistema radicular possuía desenvolvimento inadequado. Vale ressaltar que, com a aplicação de nitrogênio, a eficiência na absorção de nutrientes tende a aumentar à medida que surgem novas raízes.

No que se refere à relação entre as concentrações de nitrogênio na parte aérea e raízes do capim, foi observado que as concentrações de nitrogênio na parte aérea no primeiro, segundo e terceiro cortes do capim-braquiária (Figuras 2A, 2B e 2C) foram respectivamente 3,02; 3,35 e 3,7 vezes maiores que a concentração de nitrogênio nas raízes da gramínea (Figura 3).

A análise de variância revelou que não foi significativa a interação doses de nitrogênio $\times$ enxofre na concentração de enxofre nas folhas diagnósticas do capim-braquiária, nas lâminas foliares coletadas à época do primeiro, segundo e terceiro cortes do capim. No entanto, houve efeito isolado das doses de enxofre no primeiro e no segundo cortes do capim, com ajuste dos resultados a modelo de regressão de primeiro grau (Figuras 4A e 4B). Na amostragem do terceiro corte não houve efeito significativo para as doses de enxofre aplicadas ao solo. O intervalo de concentrações de enxofre nessas lâminas foliares variou de 1,10 a 1,58 e de 1,87 a $2,19 \mathrm{~g} / \mathrm{kg}$, respectivamente para o primeiro e segundo cortes. As concentrações de enxofre neste trabalho estão próximas daquelas encontradas por Santos (1997), para capim-braquiária submetido a doses desse nutriente em solução nutritiva.

Mattos \& Monteiro (2003) observaram no capimbraquiária concentração de enxofre de $2,81 \mathrm{~g} / \mathrm{kg}$ nas folhas
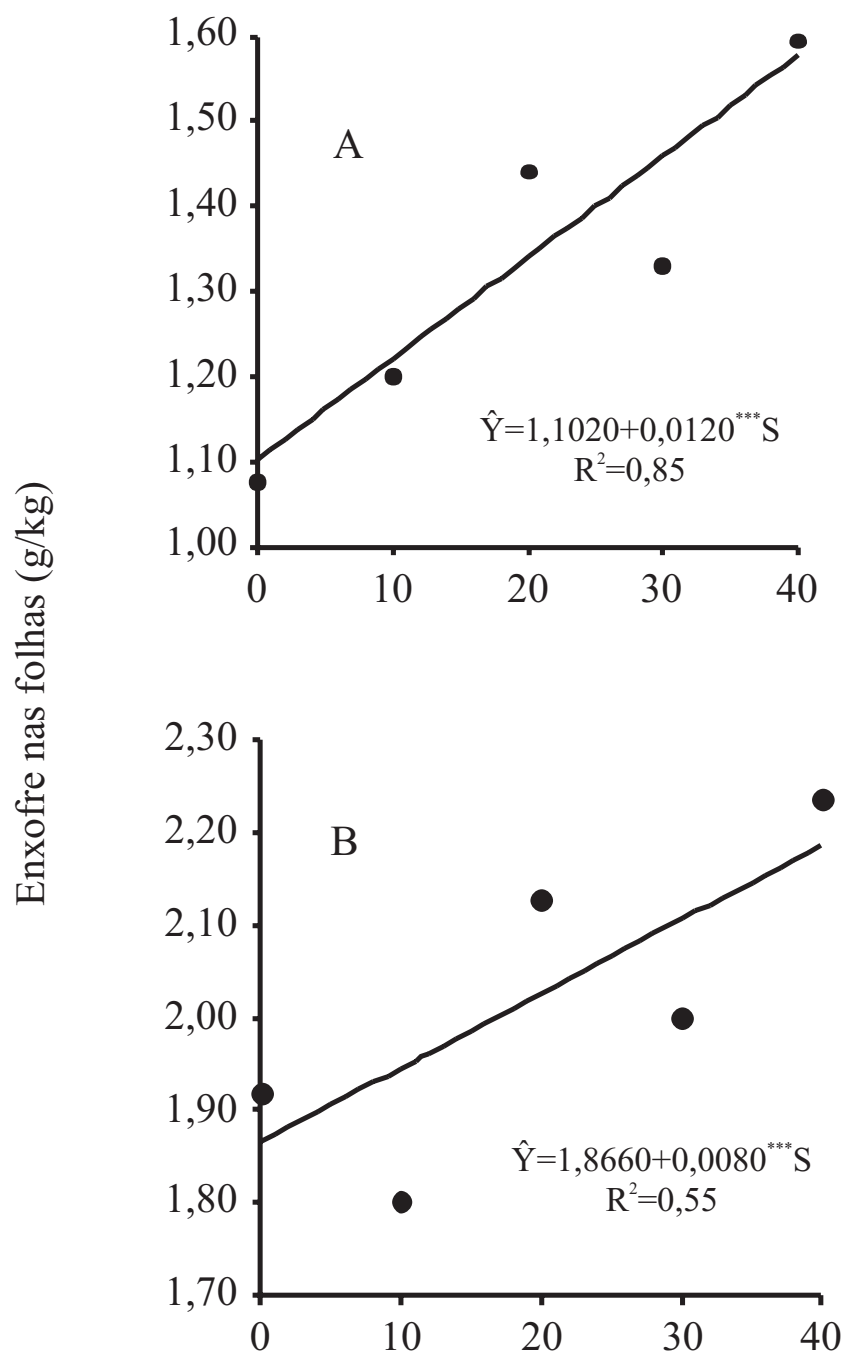

Enxofre $\left(\mathrm{mg} / \mathrm{dm}^{3}\right)$

*** Significativo a $0,1 \%$.

Figura 4 - Concentração de enxofre, no primeiro (A) e no segundo (B) cortes, em folhas diagnósticas de capim-braquiária adubado com enxofre. 
diagnósticas, que ocorreu na dose superior à maior dose do intervalo experimental $\left(60 \mathrm{mg} / \mathrm{dm}^{3}\right.$ foi a maior dose do intervalo experimental).

No terceiro corte, a não significância para as doses de enxofre pode ter ocorrido em razão da reserva desse nutriente nos colmos mais bainhas remanescentes dos cortes anteriores, e também pelas raízes terem sido suficientes para atender a demanda nutricional do capim.

A interação doses de nitrogênio $\times$ enxofre aplicadas ao solo não foi significativa para a concentração de enxofre nas raízes do capim-braquiária. No entanto, a significância foi observada para o estudo isolado das doses de nitrogênio, com ajuste ao modelo quadrático de regressão (Figura 5). A variação nessa concentração nas raízes ocorreu no intervalo de 2,29 a 1,61 g/kg, respectivamente para a ausência da aplicação do nitrogênio e para a dose de nitrogênio de $260 \mathrm{mg} / \mathrm{dm}^{3}$ (que proporcionou a mínima concentração de enxofre nas raízes). Considerando que a máxima produção de raízes foi obtida na dose $275 \mathrm{mg} / \mathrm{dm}^{3}$, pode-se considerar que provavelmente a mínima concentração de enxofre foi devida ao efeito de diluição ocasionada pela maior parte da gramínea quando submetida a doses mais elevadas de nitrogênio. Esses resultados estão próximos aos observados na implantação do capim-marandu por Batista \& Monteiro (2006), que constataram redução na concentração de enxofre nas raízes com o incremento na dose de nitrogênio na solução nutritiva. Essa diminuição da concentração de enxofre em função das doses de nitrogênio pode ser atribuída ao efeito de diluição, uma vez que, à medida que se aumentou a dose de nitrogênio, observou-se incremento da massa seca das raízes. Santos (1997) observou concentração máxima de enxofre de 2,3 g/kg na implantação do capim-braquiária.

A concentração de enxofre nas raízes do capimbraquiária foi maior que na parte aérea, diferentemente do observado para as concentrações de nitrogênio, que foram maiores na parte aérea da forrageira. Desse modo, comparando-se as máximas concentrações de enxofre da parte aérea no primeiro e no segundo cortes (Figuras 4A e 4C) com a máxima concentração de enxofre nas raízes (Figura 5), verificou-se que a concentração nas raízes foi de 1,44 e 1,04 vezes maior que aquelas observadas, respectivamente, na parte aérea do segundo e terceiro cortes do capim, indicando que o capim-braquiária concentra mais enxofre nas raízes que na parte aérea, quando comparado ao nitrogênio. Esses resultados estão de acordo com os observados por Santos (1997), que também verificou maior concentração de enxofre nas raízes que nos componentes da parte aérea do capim-braquiária.

A relação nitrogênio:enxofre nas folhas diagnósticas do capim-braquiária não apresentou significância para a interação doses de nitrogênio $\times$ enxofre, nos três cortes da gramínea.

No entanto, houve significância de maneira isolada das doses de nitrogênio, com ajuste dos resultados ao modelo quadrático de regressão, no primeiro e terceiro cortes, e ao modelo linear no segundo corte (Figuras 6A, 6B e 6C).

Para o primeiro e terceiro cortes, os máximos valores para as relações nitrogênio:enxofre foram de 16,3:1 e de 16:1, observadas nas doses de nitrogênio de 329,37 e de $394,83 \mathrm{mg} / \mathrm{dm}^{3}$, respectivamente.

Nas lâminas foliares coletadas nos três cortes do capim, a relação nitrogênio:enxofre manteve-se em torno de 7:1 nas plantas desenvolvidas sem adubação. Considerando que a relação nitrogênio:enxofre adequada para o capim deve estar em torno de 14 a 15:1 (Monteiro \& Carriel, 1987; Monteiro et al., 2004), o valor observado na ausência da adubação nitrogenada mostra que existia maior deficiência de nitrogênio que de enxofre no capim em degradação. Esta é possivelmente a razão pela qual as plantas responderam, em relação à produção de massa seca, mais à adubação com nitrogênio que com enxofre, conforme os resultados apresentados por Bonfim-Silva \& Monteiro (2006).

Esses resultados estão de acordo com os discutidos por Braga et al. (2004) para capim-mombaça submetido a

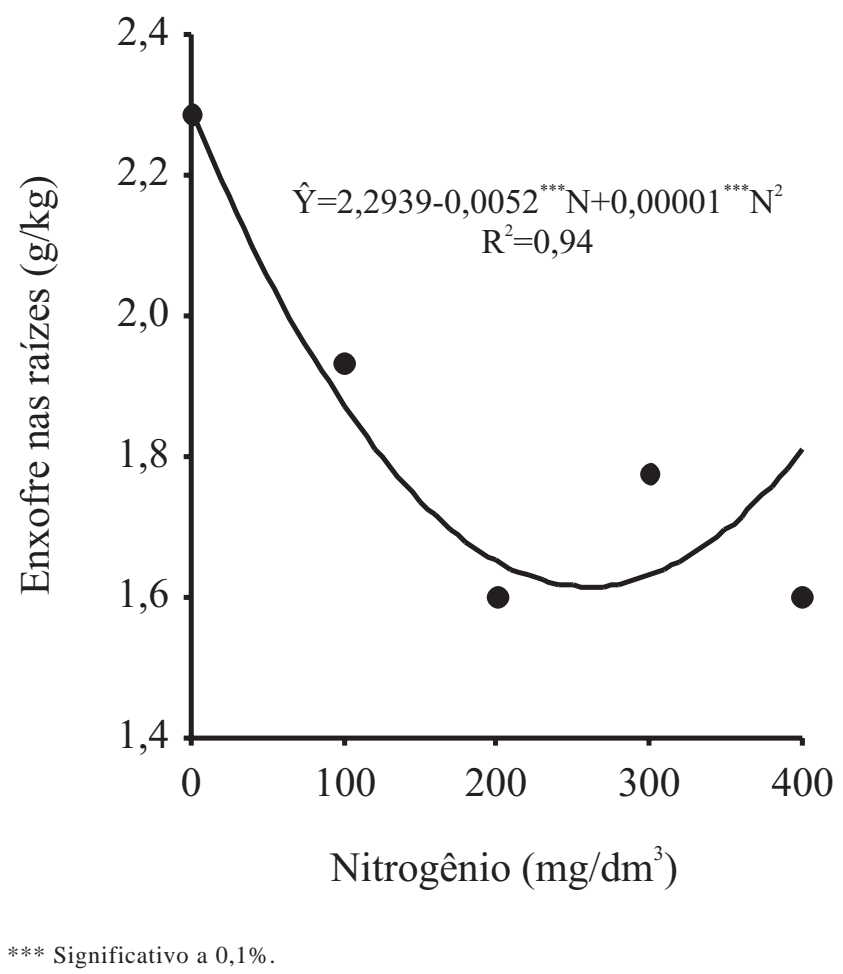

Figura 5 - Concentração de enxofre, no terceiro corte, em raízes do capim-braquiária adubado com nitrogênio. 

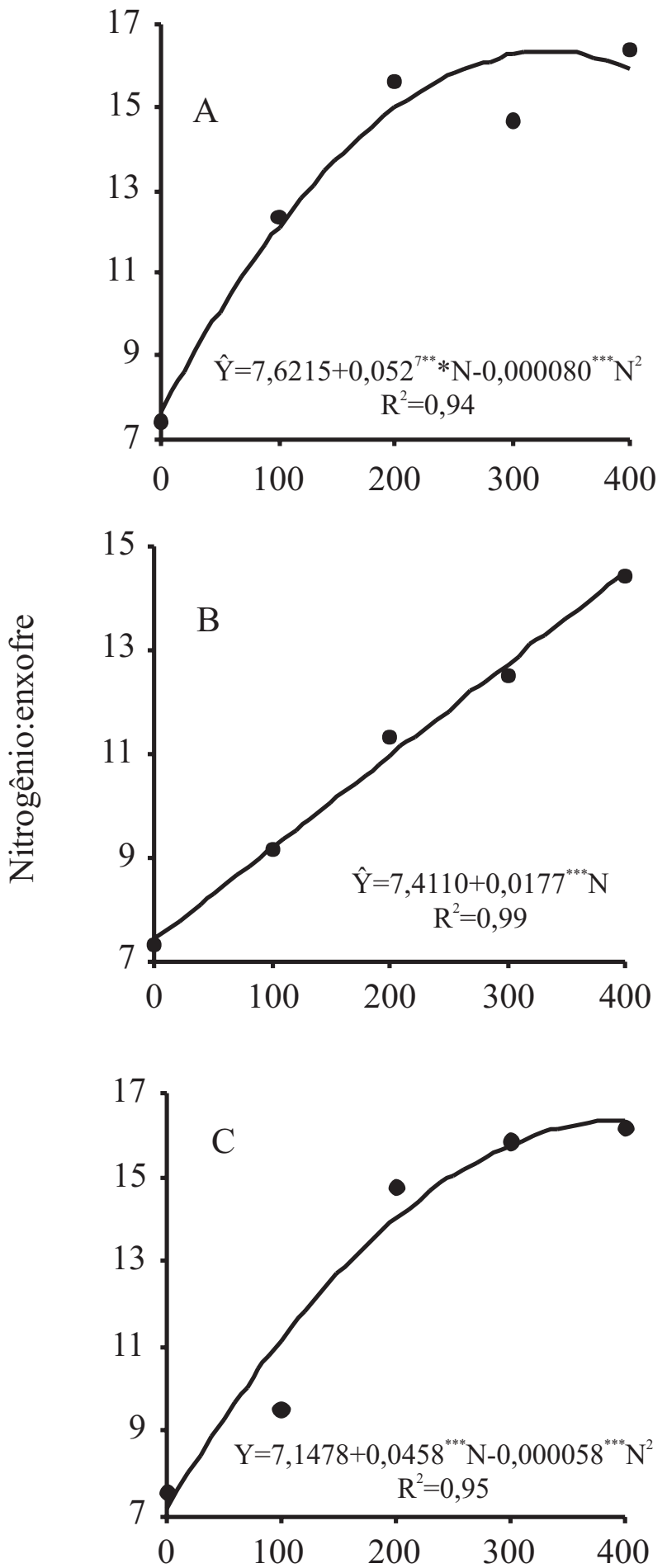

Nitrogênio $\left(\mathrm{mg} / \mathrm{dm}^{3}\right)$ doses de nitrogênio e intervalos de corte, tendo ressaltado que a relação nitrogênio:enxofre respondeu de forma quadrática à aplicação de nitrogênio, que atingiu o máximo valor na dose de nitrogênio de $380 \mathrm{~kg} / \mathrm{ha}$.

Neste experimento, confirmou-se a relevância em utilizar, além da análise foliar, a relação nitrogênio:enxofre na avaliação do estado nutricional das gramíneas forrageiras, conforme discutido por Monteiro et al. (2004).

A interação doses de nitrogênio $\times$ enxofre não foi significativa para a relação nitrogênio:enxofre nas raízes do capim-braquiária, mas significância foi observada para as doses de nitrogênio, com ajuste ao modelo de regressão de primeiro grau (Figura 7).

Considerando a não aplicação de nitrogênio e a máxima dose de nitrogênio do experimento, observou-se variação na relação nitrogênio:enxofre nas raízes de 3,2:1 a 5,4:1, respectivamente. Esses resultados são semelhantes aos observados por Monteiro (1986) em trabalho com Paspalum submetido à aplicação de enxofre, no qual verificou que tanto na aplicação quanto na não aplicação desse nutriente, a relação nitrogênio:enxofre nas raízes do capim foi de 4,1:1. Entretanto, Batista \& Monteiro (2006) não obtiveram significância para a relação nitrogênio:enxofre nas raízes do capim-marandu, tanto para as doses de nitrogênio como para as de enxofre.

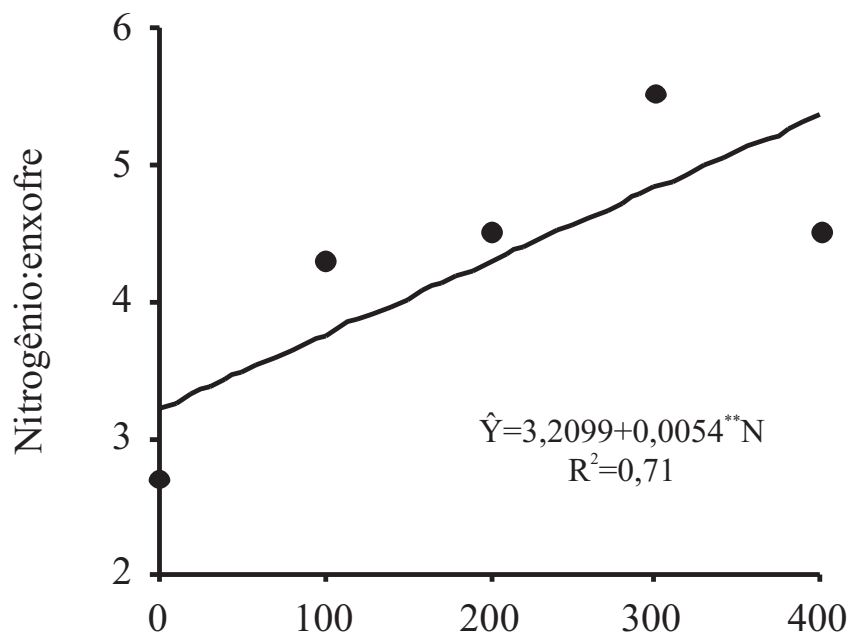

Nitrogênio $\left(\mathrm{mg} / \mathrm{dm}^{3}\right)$

\footnotetext{
** Significativo a $1 \%$.
}

Figura 7 - Relação nitrogênio:enxofre, após o terceiro corte, em raízes de capim-braquiária adubado com nitrogênio.
Figura 6 - Relação nitrogênio:enxofre, no primeiro (A), segundo (B) e terceiro (C) cortes, em folhas diagnósticas de capim-braquiária adubado com nitrogênio. 


\section{Conclusões}

O capim-braquiária em recuperação tem dependência da combinação de doses de nitrogênio e de enxofre para o valor SPAD apenas no primeiro corte da forrageira, com efeito isolado das doses de nitrogênio no segundo e no terceiro cortes. A baixa relação nitrogênio:enxofre observada, quando não foi aplicado o nitrogênio, comprova maior deficiência de nitrogênio que de enxofre no capimbraquiária em recuperação. O capim-braquiária concentra mais enxofre nas raízes que na parte aérea, quando comparado ao nitrogênio. A aplicação principalmente de nitrogênio, mas também de enxofre, influencia o estado nutricional e a sua recuperação em termos desses dois nutrientes.

\section{Referências}

BATAGLIA, O.C. Análise química de plantas. In: FERREIRA, M.E.; CRUZ, M.C.P. (Eds.). Micronutrientes na agricultura. Piracicaba: POTAFOS/CNPq, 1991. p.289-308.

BATISTA, K.; MONTEIRO, F.A. Nitrogen and sulphur in marandu Grass: relationship betweens supply and concentration in leaf tissues. Scientia Agricola, v.64, n.1, p.44-51, 2007.

BATISTA, K.; MONTEIRO, F.A. Sistema radicular do capimMarandu, considerando as combinações de doses de nitrogênio e de enxofre. Revista Brasileira de Ciência do Solo, v.30, n.5, p.821-828, 2006.

BONFIM-SILVA, E.M.; MONTEIRO, F.A.; SILVA, T.J.A. Nitrogênio e enxofre na produção e no uso de água pelo capimbraquiária em degradação. Revista Brasileira de Ciência do Solo, v.31, p.309-317, 2007.

BONFIM-SILVA, E.M.; MONTEIRO, F.A. Nitrogênio e enxofre em características produtivas do capim-braquiária proveniente de área de pastagem em degradação. Revista Brasileira de Zootecnia, v.35, n.4, p.1289-1297, 2006.

BRAGA, G.J.; LUZ, P.H.C.; HERLING, V.R.; LIMA, C.G. Respostas do capim-mombaça a doses de nitrogênio e a intervalo de corte. Acta Scientiarum. Animal Sciences, v.26, n.1, p.123-128, 2004.

BREU, J.B.R.; MONTEIRO, F.A. Produção e nutrição do capimMarandu em função de adubação nitrogenada e estádios de crescimento. Boletim de Industria Animal, v.56, n.2, p.137-146, 1999.

CECATO, U.; JOBIM, C.C.; REGO, F.C.A. et al. Sistema radicular - o componente esquecido das pastagens. In: SIMPÓSIO SOBRE MANEJO ESTRATÉGICO DE PASTAGEM, 2., 2004, Viçosa, MG. Anais... Viçosa, MG: UFV; DZO, 2004. p.159-207.

CHAPMAN, S.C.; BARRETO, H.J. Using a chlorophyll meter to estimate specific leaf nitrogen of tropical maize during vegetative growth. Agronomy Journal, v.89, n.1, p.557-562, 1997.

COLOZZA, M.T. Rendimento e diagnose foliar dos capins aruana e mombaça cultivados em Latossolo VermelhoAmarelo adubado com doses de nitrogênio. 1998. $127 \mathrm{f}$. Tese (Doutorado em Solos e Nutrição de Plantas) - Escola Superior de Agricultura “Luiz de Queiroz”, Universidade de São Paulo, Piracicaba.

COLOZZA, M.T.; KIEHL, J.C.; WERNER, J.A. et al. Respostas de Panicum maximum cultivar Aruana a doses de nitrogênio. Boletim de Indústria Animal, Nova Odessa, v.57, n.1, p.21-32, 2000.

LAVRES JR., J.; MONTEIRO, F.A. Diagnose nutricional de nitrogênio no capim-Aruana em condições controladas. Revista Brasileira de Ciência do Solo, v.30, n.5, p.829-837, 2006.
LAVRES JR., J.; MONTEIRO, F.A. Combinações de doses de nitrogênio e potássio para a produção e nutrição do capim-Mombaça. Boletim de Indústria Animal, v.59, n.2, p.101-114, 2002.

LITTELL, R.C.; MOTT, G.O. Computer assisted design and analysis of response surface experiments in agronomy. Soil and Crop Society of Florida Proceedings, v.34, n.1, p.94-97, 1975.

MANARIN, C.A.; MONTEIRO, F.A. Nitrogênio na produção e diagnose foliar do capim-mombaça. Boletim de Industria Animal, v.59, n.2, p.115-123, 2002.

MATTOS, W.T.; MONTEIRO, F.A. Produção e nutrição de capimbraquiária em função de doses de nitrogênio e enxofre. Boletim de Indústria Animal, v.60, n.1, p.1-10, 2003.

MENGEL, K. KIRKBY, E.A. Principles of plant nutrition. Dordrecht: Kluwer Academic Publishers, 2001. 849p.

MINOLTA CAMERA. Manual for chlorophyll meter SPAD502. Osak: 1989. 22p.

MONTEIRO, F.A. Amostragem de solo e de planta para fins de análises químicas: métodos e interpretações de resultados. In: PEDREIRA, C.G.S.; MOURA, J.C.; DA SILVA, S.C. et al. (Orgs.) Piracicaba: FEALQ, 2005. p.151-179.

MONTEIRO, F.A. Sulphur fertilization and nutrient distribution in a florida spodsol profile under white clover-Pensacola Bahiagrass. 1986. 182f. Thesis (PhD in Soil Science) - University of Florida.

MONTEIRO, F.A.; CARRIEL, J.M. Aplicação de níveis de enxofre na forma de gesso para o cultivo do capim-colonião em dois solos arenosos do Estado de São Paulo. Boletim de Indústria Animal, v.44, n.2, p.335-347, 1987.

MONTEIRO, F.A.; COLOZZA, M.T. WERNER, J.C. Enxofre e micronutrientes em pastagens. In: SIMPÓSIO SOBRE MANEJO DA PAStAGEM, 21., 2004, Piracicaba. Anais... Piracicaba: FEALQ, 2004. p.279-301.

RODRIGUES, R.C.; PEREIRA, W.L.M.; MATTOS, H.B. et al. Concentração de nitrogênio nos componentes da parte aérea do capim-braquiária em função da aplicação de calcário, nitrogênio e enxofre. Revista Agricultura Tropical, v.7, p.3-9, 2003.

SANTOS, A.R. Diagnose nutricional e respostas do capimbraquiária submetido a doses de nitrogênio e enxofre. 1997. 115f. Tese (Doutorado em Solos e Nutrição de Plantas) Escola Superior de Agricultura "Luiz de Queiroz”/Universidade de São Paulo, Piracicaba.

SARMENTO, P.; RODRIGUES, L.R.A.; LUGÃO, S.M.B. et al. Sistema radicular do Panicum maximum Jacq. Cv.IPR-86 Milênio adubado com nitrogênio e submetido à lotação rotacionada. Revista Brasileira de Zootecnia, v.37, n.1, p.27-34. 2008.

SARRUGE, J.R.; HAAG, H.P. Análises químicas em plantas. Piracicaba: ESALQ, Departamento de Química, 1974. 56p.

SILVEIRA, C.P.; NACHTIGALL, G.R.; MONTEIRO, F.A. Norms for the diagnosis and recommendation integrated system for Signal grass- Scientia Agricola, v.62, n.6. p.513-519, 2005.

SOARES FILHO, C.V. Tratamentos físico-químico, correção e adubação para recuperação de pastagens. In: ENCONTRO SOBRE RECUPERAÇÃO DE PASTAGENS, 1., 1993. Nova Odessa. Anais... Nova Odessa: Instituto de Zootecnia, 1993. p.79-117.

SOARES FILHO, C.V.; MONTEIRO, F.A.; CORSI, M. Recuperação de pastagens degradadas de Brachiaria decumbens. 1. Efeito de diferentes tratamentos de fertilização e manejo. Pasturas Tropicales, v.14, n.2. p.1-6, 1992.

STATISTICAL ANALYSIS SYSMTEM - SAS. The SAS system for Windows, Release 6.08 SAS Institute: Cary, 1996, 633p.

WERNER, J.C.; PAULINO, V.T.; CANTARELLA, H. et al. Forrageiras. In: RAIJ, B. van; CANTARELLA, H.; QUAGGIO, J.A. et al. (Eds.). Recomendações de adubação e calagem para o estado de São Paulo, 2.ed. Campinas: Instituto Agronômico, Fundação IAC, 1996. p.263-273. (IAC. Boletim Técnico, 100). 